\title{
La obra latina del converso Paulus Ricius ( $†$ 1541/42): catalogación bibliográfica
}

Sandra I. Ramos Maldonado *

Universidad de Cádiz

\begin{abstract}
Aunque el converso Paulus Ricius, junto con Pico y Reuchlin, sentó las bases para posteriores elucubraciones sobre la «cábala» cristológica y jugó un notable papel en las principales disputas teológicas y filosóficas del momento, sus escritos son prácticamente desconocidos en España y no existe todavía estudio, edición ni traducción de los mismos. En este trabajo se ofrece la edición y traducción de algunas fuentes contemporáneas, un catálogo de todos sus escritos en latín y una actualización bibliográfica sobre la materia.
\end{abstract}

Palabras clave: Paulus Ricius; hebraísmo cristiano en España; ediciones; bibliografía; Humanismo.

The Latin Works by the Convert Paulus Ricius (D. 1541-42): A Bibliographical Catalog.Although the convert Paulus Ricius, along with Pico and Reuchlin, settled the basis for further speculations about Christological "Cabala," and he also played an important role in the theological and philosophical controversies of his time, his writtings are nearly unknown in Spain and they have not been studied, edited or translated yet. This article offers the edition and translation of some contemporary sources, a catalogue of all his works written in Latin and a bibliographical updating about the subject.

KeYwords: Paulus Ricius; Spanish Christian Hebraism; Editions; Bibliography; Humanism.

En 1579 el obispo de Albarracín Bernardino Gómez Miedes, por entonces arcediano de Sagunto y canónigo de Valencia, publica en la ciudad del Turia la segunda y definitiva versión de sus enciclopédicos Commentarii de sale ${ }^{1}$, en

*sandra.ramos@uca.es

${ }^{1}$ Para más detalles sobre dicha obra, cf. nuestro trabajo Bernardino Gómez Miedes. Comentarios sobre sal. Introducción, edición crítica, traducción, notas e índices, 3 vols. (AlcañizMadrid 2003), edición que constituye una revisión y ampliación de mi Tesis Doctoral (Cádiz 1995) realizada bajo la dirección de J. Gil Fernández y J. Mª . Maestre Maestre. Las referencias y citas que realizo de esta obra corresponden a mi edición, especificando, tras la fórmula MIED. sal., el número del libro, del capítulo y del parágrafo correspondiente. 
un apéndice de los cuales cita a Naḥmánides, máximo representante del círculo de cabalistas de Gerona del siglo XIII, y a Paulus Ricius, un judío converso, Israelita doctissimus, cuyo papel en la presentación de la cábala cristiana ${ }^{2}$, que anunciaba todos los misterios del cristianismo, fue fundamental:

Nam et Paulus Ritius ${ }^{3}$, Israelita doctissimus, medicus Maximiliani imperatoris, ad fidem et religionem Christi conuersus, opus grauissimum de mysteriis diuinis edidit, quod Sal foederis inscripsit ${ }^{4}$.

El extenso apéndice, inexistente en la editio princeps de 1572, finaliza con la siguiente referencia a la obra cabalística del médico del emperador Maximiliano y constituye una glosa a Levítico 2:13:

Hoc quippe sale pacatae diuinae mentes et summum in eos fauorem et assiduam liberalitatem et dona quaeuis optima refundere non cessabant, quinimmo ad non dubiam uocari se putabant Dei amicitiam et perpetuum cum eo amorem conciliandum. Quod equidem non aliam ob caussam factum opinor quam ob diuinam aliquam in sale inclusam uim, quae perapte sacrificii rationem exprimeret, cum nulla quidem olim sacrificia neque pacta sine sale fierent, quae Deo insuauia non essent.

Quemadmodum Diuina id Scriptura comprobat: «Quicquid obtuleris -inquiens- sacrificii sale condies nec auferes salem foederis Dei tui de sacrificio tuo. In omni insuper oblatione offeres salem» [in marg.: leu. 2].

\footnotetext{
${ }^{2}$ Los estudios críticos sobre la mística judía se refieren a la kabbalá, según expresión de G. Vajda (cf. Introduction à la pensée juive au Moyen âge, Paris 1947, pág. 199, cit. F. SECRET, La kabbala cristiana del Renacimiento, Madrid 1979, pág. 7), a «un producto que comprende, además del antiguo esoterismo judío, el corpus íntegro de los escritos talmúdicos y midráshicos, así como la cuasi-totalidad de las especulaciones teológico-filosóficas del período judeo-árabe». La evolución semántica popular del término «cábala» en castellano, ajena al ambiente judío, lo había llevado a englobar ocasionalmente el ocultismo. En el presente trabajo utilizaré preferentemente la formulación «cábala cristiana» para aludir a interpretaciones cristológicas de textos místicos judíos por autores cristianos.

${ }^{3}$ El apellido de este judío converso se ha transmitido bajo las formas de Ricius, Riccius y Ritius (también era conocido como Paulus Israelita). He optado por la forma Ricius, utilizada sistemáticamente en las portadas de todos sus libros, así como por la mayoría de sus estudiosos. Cuestión aparte es la transcripción de este nombre en las lenguas modernas. La dudosa procedencia de Ricius (Alemania o Italia) provoca transcripciones de este tipo: Paul Ritz, Paolo Ricci, Pablo o Paulo Ricio, Rici. He optado por dejar tal cual el nombre latinizado.

${ }^{4} C f$. MIED. sal. V, 13, 8, un apéndice de la $2^{\mathrm{a}}$ edición. Las letras en negrita son mías, y salvo explicitado en contrario, las traducciones también: 'En efecto, Paulus Ricius, sabio israelita y médico del emperador Maximiliano, convertido a la fe y religión de Cristo, publicó una obra de enorme peso acerca de los misterios divinos, que tituló La sal de la alianza'.
} 
Quin et aliis locis pactum salis simili ratione atque mysterio seruandum praecipitur. Vnde apud Hebraeos nullum sine sale feriebatur foedus, hoc est, sine sacrificio quod nullum sine sale fiebat ${ }^{5}$.

El autor de los Commentarii de sale analiza, pues, el significado bíblico del «pacto de sal», al que los hebreos manifestaron tanto respeto y solemnidad, que pensaron que no había ninguno más sólido ni más inquebrantable que el sellado con el blanco condimento. De hecho fue constituido, según explica Gómez Miedes, sólo dos veces por Dios. Una vez con Aarón, el supremo sacerdote de la Ley, cuando, por la custodia del sacerdocio y por realizar bien la función del santuario, le fueron entregadas a él y a sus descendientes las primicias de los frutos, aseguradas para siempre con un pacto de sal ${ }^{6}$. En segundo lugar, la alianza de sal se pactó con el profeta y rey David, cuando, empezando a reinar Abías, hijo de Roboam, habló ante Jeroboam y el pueblo de Israel sublevado por éste ${ }^{7}$.

Pero, a decir de Gómez Miedes, la razón de por qué este pacto era consagrado con sal e inviolable y era llamado por la Escritura «eterno» no había sido mencionada por nadie, ni siquiera por san Jerónimo, que en sus Cuestiones hebreas escribe $^{8}$ :

Pactum salis in quibusdam locis pro lege ponitur, quae omnium condimentum est, hic uero pro domo Dauid, qui uniuerso Israeli fuit condimentum.

${ }^{5}$ Cf. MIED. sal. V 12, 7-8. Trad.: 'Lo cierto es que las mentes divinas aplacadas con esta sal no dejaban de esparcir un favor absoluto hacia ellos, una continua afabilidad y cualquier óptimo don, e incluso pensaban que ellos eran llamados para una alianza segura con Dios y para ganarse su amor eterno. Y creo que esto sucedió no por otra razón que por alguna fuerza divina que hay contenida en la sal, que podría reproducir la naturaleza del sacrificio, pues antaño no había sacrificios ni pacto que no se realizara sin sal sin desagradar a Dios. Así, por ejemplo, se confirma en las Sagradas Escrituras: «Toda oblación que presentes la condimentarás con sal y no dejarás que falte la sal de la alianza de Dios en tu sacrificio. En toda oblación ofrecerás sal». E incluso en otros lugares se ordena que el pacto de sal debe respetarse por una razón y misterio semejantes. De ahí que entre los hebreos ningún acuerdo se concluía sin sal, es decir, sin un sacrificio que no se hiciera sin sal'.

${ }^{6}$ Cf. vulg. Num. 18, 19: «Omnes primitias sanctuarii, quas offerunt filii Israel Domino, tibi dedi ac filiis et filiabus tuis, iure perpetuo, pactum scilicet salis est sempiternum coram Domino, tibi ac filiis tuis».

${ }^{7}$ Cf. vulg. Paralip. 2, 13: «Num ignoratis quod Dominus Deus Israel dederit regnum Dauidi super Israel in sempiternum, ipsi et filiis eius in pactum salis?».

${ }^{8}$ Cf. HIER. quaest. hebr. [Opera omnia, Parisiis 1546] t. III, f. $94 \mathrm{~m}$. Trad.: 'El pacto de sal se aplica en ciertos lugares como ley, que es el condimento de todas las cosas, pero aquí David lo aplica como casa, que fue el condimento para toda Israel'. 
Es por ello que el canónigo valenciano concluye que el «pacto de sal» parece revelar misterios mucho más profundos, cuyo verdadero origen debe hacerse remontar más atrás en el tiempo, desde el principio del mundo. En este contexto introduce la obra del sabio gerundense Naḥmánides:

Sed de tali quidem pacto longe maiora mysteria eruenda sunt ueraque illius origo multo altius ab ipso mundi principio repetenda. Quandoquidem ut ex eisdem Hebraeorum monimentis apparet, quidam magni certe nominis Rabi Mosses Gerundensis, in magnis suis Commentariis super Genesim, loquens de pactis, expresse inquit: «Pactum percussum fuisse cum sale a diebus creationis et origine mundi». Ideoque longe alio quam ad summum sacerdotium et regnum Israeliticum tantam pacti immutabilitatem referre necesse est ${ }^{9}$.

Esta actitud de Gómez Miedes entronca directamente con el interés que surgió en la Academia Florentina por comprender la lengua hebrea y los textos que no pertenecían al canon bíblico. Este interés, en efecto, estaba vinculado a una más amplia exploración de los prisci theologi, cuyo conocimiento secreto procedente de la época de la inocencia del hombre del Edén, o al menos de una época más próxima que la real, se pensaba que había sido transmitido ininterrumpidamente aunque de modo oral y permanecía accesible bajo el texto de cualesquiera obras que resultaran de gran oscuridad ${ }^{10}$. La Academia Florentina dio mucha importancia a este hecho y percibió numerosas conexiones entre las diferentes tradiciones de la sabiduría del mundo antiguo, dando lugar a un gran diálogo y verdadero encuentro entre las formas tradicionales representativas del mundo occidental: por una parte llega desde Bizancio a Florencia a través de Gemistos Plethon el Corpus Hermeticum y el Corpus Platonicum, que serán traducidos del griego al latín; por otro lado, llega la sabiduría de la mística hispano-judía a través de la diáspora judía procedente de Provenza, Gerona y Toledo ${ }^{11}$.

${ }^{9}$ Cf. MIED. sal. V 12, 11. Trad.: 'Pero sobre tal pacto deben revelarse misterios mucho mayores y hacer remontar mucho más atrás, desde el principio del mundo, su verdadero origen. Según se muestra a partir de los propios documentos de los hebreos, cierto Rabí de gran renombre, Moses de Gerona, en sus Comentarios sobre el Génesis, hablando acerca de los pactos, dice bien claramente: «El pacto fue concluido con sal después de los días de la creación y el origen del mundo»' .

${ }^{10}$ Cf. C. P. Thompson, La lucha de las lenguas. Fray Luis de León y el Siglo de Oro en España (Valladolid $1995^{2}$ ), pág. 161.

${ }^{11}$ Para una presentación de la historia del misticismo judío, véase G. C. Scholem, Kabbalah (New York 1978); ID., La Cábala y su simbolismo (Madrid 1978). 
¿Hasta qué punto podemos hablar de influencia de la cábala cristiana en la obra del humanista Gómez Miedes? Según concluimos en un trabajo anterior ${ }^{12}$, las concepciones vigentes en el siglo XVI sobre la lengua hebrea, la Biblia y la cábala cristiana aparecen reflejadas fundamentalmente en el último libro de sus Commentarii de sale, pero este reflejo es muy tenue, apenas insinuado veladamente y sólo evidente en la segunda edición de la obra. Conoce la cábala (aunque no la cite explícitamente), conoce las técnicas de exégesis judía y las usa (aunque no falte en su obra el ataque a los judíos), conoce y cita los nombres y las obras de dos importantes cabalistas, uno judío y otro converso (uno de ellos prohibido en el Index Inquisitorial de 1559) y no los condena... En definitiva, hace uso de la cábala y sus técnicas al servicio de sus argumentos teológicos y de la finalidad de su obra, pero el acercamiento a dicha corriente y en definitiva al pueblo judío parece un tanto superficial, como lo demuestra sobre todo el hecho de que el procedimiento de la cábala alfabetaria, o de asociación y permutación de letras hebreas es lo más utilizado por el humanista alcañizano, pero como un juego y «vacío» (no faltan incluso los errores en el uso de las letras hebreas).

Ahora bien, dado que en España los estudios sobre dicho movimiento y su influencia en nuestros humanistas son aún escasos ${ }^{13}$, en primer lugar deberían realizarse en España ediciones críticas modernas, traducciones y estudios de las obras de los seguidores o continuadores de Pico, como Paulus Ricius ${ }^{14}$, labor esta que ha de llevarse a cabo según los planteamientos de la Filología Clásica y los estudios humanísticos actuales, en colaboración con el área de estudios hebraicos,

${ }^{12} C f$. S. Ramos Maldonado, «Sal: una interpretación trinitaria del Tetragrámmaton y un no bre de dios según un humanista (¿cabalista?) cristiano del siglo XVI», Calamus Renascens 5-6 (2004-2005), págs. 193-222. Concluimos este trabajo con la constatación de similitudes entre la obra de Gómez Miedes, donde aplica las técnicas de exégesis judía, y el texto del alquimista y cabalista francés Blaise de Vigenère, y su inconcluso Traicté $d u$ fue et $d u$ sel, editado póstumamente en París, en 1618, quien realiza la misma interpretación trinitaria del nombre hebreo de la sal. En la búsqueda de la fuente común utilizada, así como en el análisis de las semejanzas y divergencias entre ambos autores estoy trabajando en la actualidad.

${ }^{13}$ Una referencia pormenorizada de dichos estudios con un resumen de las conclusiones más significativas puede consultarse en nuestro trabajo «La cábala cristiana en España: a propósito de la obra latina de Paulus Ricius israelita $(† 1541) »$, en J. M. ${ }^{a}$ Maestre Maestre, J. Pascual Barea, L. Charlo Brea (eds.), Humanismo y pervivencia del Mundo Clásico. Homenaje al Profesor Antonio Prieto (Alcañiz-Madrid), en prensa.

${ }^{14}$ Algunos investigadores suelen considerar a Pico, Reuchlin y Ricius los tres «fundadores» que sentaron las bases de todas las especulaciones posteriores sobre la cábala cristológica, $c f$. W. VARNER, «The Christiam use of Jewish Numerology», The Master's Seminary Journal 8, 1997, págs. 47-59:51); W. Schmidt-Biggemann, Philosophia Perennis: Historical Outlines of Western Spirituality in Ancient, Medieval and Early Modern Thought (Dordrecht 1998), cf. § 3.5. Christian Cabala I: Giovanni Pico, Johannes Reuchlin and Paulus Ricius: págs. 93-116. 
paso previo indispensable, en nuestra opinión, para poder demostrar el grado de influencia en los humanistas españoles de este movimiento religioso de moda en la Europa del siglo XVI. El objetivo, pues, del presente trabajo es ofrecer una puesta al día bibliográfica de la obra latina del judío converso Paulus Ricius, para lo cual realizamos previamente la edición y traducción de determinadas fuentes contemporáneas que se hacen eco de la obra del hebraísta cristiano.

\section{Paulus Ricius en la fuentes CONTEMPoráneas}

En España es prácticamente desconocida la obra de este converso y hebraísta cristiano, de la que no existe estudio, edición ni traducción ${ }^{15}$. En la actualidad podemos citar solamente los trabajos de Schmidt-Biggemann ${ }^{16}$, Tilg ${ }^{17} \mathrm{y}$, en especial, de Roling $^{18}$, como los más específicos en el análisis de la obra de Ricius y su repercusión

${ }^{15}$ W. L. GUNDERSHEIMER subrayaba ya en 1963 que «biographical material on Ricius is very scanty» (cf. su «Erasmus, Humanism and the Christian Cabala», Journal of the Warburg and Courtauld Institutes 26 (1963), págs. 38-52:40, n. 10). Fuera de nuestras fronteras es todavía hoy muy escaso el conocimiento de este converso, cuya personalidad y obra encandiló a Erasmo. J. L. Blau, en su The Christian Interpretation of the Cabala (New York 1944), págs. 67-74), realiza la primera traducción, inglesa, de una de las obras de Ricius, la In cabalistarum seu allegorizantium eruditionem Isagoge (Augsburg 1515), traducción que lleva a Gundersheimer («Erasmus, Humanism and the Christian Cabala», pág. 49, n. 56) a reconocer «an admirable example of the lucidity of Ricius's cabalistical explanations».

${ }^{16}$ Schmidt-Biggemann, Philosophia perennis, págs. 160-168, 175-179, 272-286; ID., «Christian Kabbala: Joseph Gikatilla (1247-1305), Johannes Reuchlin (1455-1522), Paulus Ricius (d. 1541), and Jacob Böhme (1575-1624)», en The Language of Adam / Die Sprache Adams, ed. A. CoudERT (Wiesbaden 1999), págs. 81-122.

${ }^{17}$ S. TILG, «Zu Paulus Ricius (ca. 1480-1541/42): eine außergewöhnliche Karriere in der Zeit des humanismus», Aschkenas 16 (2006), págs. 561-582; ID., «Aristoteles und die Kabbala - Zu Leben und Werk des Paulus Ricius (ca. 1480-1541/42)», en XIII Congress of the International Association of Neo-Latin Studies (Budapest 6.-13. August 2006).

${ }^{18}$ B. Roling, Crederemore peripatetico. Christliche KabbalahundaristotelischeNaturphilosophie im Werk des Paulus Ritius (Diss. Münster 2002); ID. «Prinzip, Intellekt und Allegorese im Werk des christlichen Kabbalisten Paolo Ricci (gest. 1541)», en G. VeltRI - A. WinkelmanN (eds.): An der Schwelle zur Moderne. Juden in der Renaissance (Leiden 2003), págs. 155-187; ID., «Mediatoris fungi munere: Synkretismus im Werk des Paolo Ricci», en W. Schmidt-Biggemann (ed.), Reuchlin und die christliche Kabbala (Sigmaringen 2003), págs. 77-100; ID. «Maimonides im Streit der Konfessionen: Die 'Statera prudentum' des Paulus Ritius und die christliche Neulektüre des Maimonides im 16. Jahrhundert», en G. Veltri, G. Necker (eds.), Gottes Sprache in der philologischen Werkstatt (Leiden 2004), págs. 149-168; ID., «Conversio and Concordia: The 'Statera prudentum' of the Jewish convert Paolo Ricci $(\dagger 1541) »$, en JAN N. BREMMER, WOUT VAN BEKKUM, ArIE L. MolendiJK (eds.), Cultures of Conversion (Leuven 2006), págs. 53-64; ID., Christliche 
en el ambiente religioso del norte de Europa, así como su papel en las principales disputas teológicas y filosóficas del momento. Debería abordarse por ello en primer lugar una labor filológica de edición y traducción de la obra latina completa de Ricius para poder dilucidar su grado de influencia en nuestros humanistas y escritores.

Aunque ciertos episodios de su vida son mejor conocidos, su lugar de nacimiento sigue permaneciendo en la nebulosa, como apunta Secret, a pesar de los estudios más recientes, como los de Roling, quien lo hace oriundo de Trento, hijo de un obispo de origen alemán y educado entre eruditos judíos del norte de Italia. No obstante, las fuentes más antiguas documentadas, como veremos a continuación, apuntan a su origen y nacimiento alemán. Esta dudosa procedencia de Ricius (Alemania o Italia) ha dado lugar, como hemos anotado, a transcripciones de su nombre tales como Paul Ritz, Paolo Ricci, Pablo Ricio o Rici. Sea como fuere, en lo que coinciden las fuentes y los estudios modernos es que su bautismo cristiano se sitúa en la Italia de principios de siglo, siendo el teólogo Frederigo Gomes de Lisboa ${ }^{19}$ quien inspiró su conversión. Roling realiza un esbozo biográfico del israelita en los siguientes términos: estudió medicina y filosofía en Padua, donde conoció al Cardenal Cajetan (también conocido como Gaetanus, Tommaso de Vio [1469-1534]) y se familiarizó con los escritos de la Academia platónica de Florencia y de los filósofos paduanos de la naturaleza, cuyo averroísmo adoptó en parte. En Pavía entró en contacto con la filosofía especulativa de Pico, que compartirá el resto de su vida. Aunque ocupó una cátedra de medicina y lenguas orientales en su universidad «natal», se trasladó al viejo Imperio donde, después de algunos puestos intermedios, sus éxitos como médico lo llevaron a la corte del emperador Maximiliano. En Alemania entró en contacto con un gran número de humanistas, granjeándose también muy pronto numerosos enemigos. Gracias a su amistad con el emperador le fue concedido el título de barón, con el que obtuvo independencia económica así como libertad intelectual en muchos aspectos hasta su muerte en 1541.

Kabbalah und aristotelische Naturphilosophie im Werk des Paulus Ritius (gest. 1541) (Tübingen 2007); ID., «Ritius, Paulus», en F. J. WorstвROcK (ed.), Die Deutsche Literatur des Mittelalters. Verfasserlexikon. Deutscher Humanismus 1480-1520 (Berlin/New York 2007 -).

${ }^{19}$ Cf. J. de Carvalho, «Gomes de Lisboa e o Averroista Nicoletto Vernia», en Estudios sobre a cultura portuguesa do século XV. Acta Univ. Conimbrigensis 1 (Coimbra 1949), págs. 200-201 y 255-256; V. MuÑoz Delgado, «La lógica hispano-portuguesa hasta 1600», Revista de Historia de las Ciencias Eclesiásticas de España 4 (1972), págs. 65-66; A. MoreIra DE SÁ, Humanistas portugueses em Itália. Subsídios para o estudo de Frei Gomes de Lisboa, dos dois Luíses Teixeiras, de João de Barros e de Henrique Caiado (Lisboa 1983); J. CerqueIra Goncalves, «Frei Gomes de Lisboa», en P. Calafate (ed.), Historia do pensamento filosofico português, vol. 1: Idade Média. (Lisboa 1999), págs. 279-295; A. d'Ors, «Gometius Hispanus Ulixbonensis O.F.M.Conv. (†1513)», Análise 23 (2002), págs. 95-144. 
Hasta aquí, en efecto, el esbozo biográfico que B. Roling ofrece en sus estudios sobre la influencia de la filosofía natural aristotélica y la cábala cristiana en la obra de Paulus Ricius, en los que, sin embargo, las referencias a los textos y autores contemporáneos que se hacen eco de las actividades y la producción del hebraísta no van más allá de las consabidas epístolas de Erasmo. Asimismo, el índice bibliográfico que el moderno investigador alemán ofrece de sus escritos ${ }^{20}$ creemos debe ser revisado y completado. En el momento actual de nuestra investigación, en la que intentamos dilucidar el grado de influencia de los hebraístas cristianos en determinados humanistas españoles, el establecimiento de dicho catálogo bibliográfico nos parece fundamental, para lo cual consideramos necesario, además de consultar los archivos de las bibliotecas, localizar, estudiar y contrastar los datos que nos suministran las fuentes contemporáneas, algunas de las cuales se editan y traducen por primera vez a una lengua moderna o al español en el presente trabajo.

\subsection{Referencias de autores contemporáneos: de Erasmo (1516) a Pedro Ciruelo (1538)}

1.1.1. De ERasmo de RotTerdam se conserva, en efecto, una carta sobre Ricius dirigida a Bartholinus en 1516, -la referencia más antigua hasta el momento, externa a la catalogación bibliográfica de su obra-, donde se realiza un elogio del médico alemán (transcribimos a continuación y traducimos en nota sólo la parte de la misiva que contiene el encomio):

Erasmus Rot(erodamus) Ricardo Bartholino s(alutem)d(icit). [...] Paulus Ricius sic me proximo colloquio rapuit, ut mira quaedam me sitis habeat, cum homine saepius ac familiarius conferendi sermonem. Praeter Hebraeae linguae peritiam, quantum ille tenet philosophiae! quantum theologiae! tum quae animi puritas, qui discendi ardor, qui docendi candor, quae disputandi modestia! Mihi sane vir ille primo statim gustu placuit olim Papiae, cum illic philosophiam profiteretur. Nunc propius intuito magis etiam placet. Is demum vere mihi videtur Israelitam agere suoque cognomini pulcre respondere: cuius omnis voluntas, omnis cura, omne ocium ac negocium, in divinis est literis. Dignus est nimirum animus, cui ocium contingat quam maxime honorificum. Eruditissimo eruditorum omnium Maecenati Cardinali Gurcensi facito me commendatum. Bene vale. Antuerpia 10 Martii, Anno $1516^{21}$.

\footnotetext{
${ }^{20}$ Cf. Roling, Christliche Kabbalah, págs. 549-550.

${ }^{21}$ Cf. LB. 210. Trad.: 'Erasmo de Róterdam saluda a Ricardo Bartolino: [...]. Paulus Ricius me cautivó de tal forma durante nuestra última conversación, que soy preso de una asombrosa sed de hablar con mayor frecuencia y confidencialidad con tal hombre. Además de su maestría en la 
Cuatro años después, Erasmo escribe al propio Ricius y se dirige a él en términos elogiosos muy similares a los empleados con Bartholinus. La admiración del humanista holandés por el converso se refleja teñida de fina ironía y sin fisuras en ambas misivas: la conversación erudita del alemán, su dominio de la lengua hebrea, sus conocimientos filosóficos y teológicos pugnan a la par con su índole personal, su ingenuidad, modestia y candor. En esta carta Erasmo, por otro lado, además de testimoniar su más sincero afecto y admiración por el converso, deja traslucir su opinión sobre el negotium cabalisticum. Transcribimos completa dicha epístola:

Erasmus Rot(erodamus) Paulo Ritio, philosopho consummatissimo, s(alutem) d(icit). Libellus tuus, eruditissime Riti, me paulo aequiorem reddidit negocio Caballistico: quanquam antehac non eram admodum infensus, siquidem ignoscendum arbitror ut humanum uicium, si quisque faueat iis studiis in quibus et plurimum insumpsit temporis et se praecipue valere confidit. Coeterum istos quis ferat, qui quicquid non intelligunt tam acerbis tamque pertinacibus odiis persequuntur? Neque vero uno nomine mihi placuit opus. Eruditio quae tibi perpetua est, hic mihi non potuit esse noua. Sed in primis arrisit candor ille et perspicuitas, quae rem ita ponit ob oculos ut caeco quoque posse esse conspicua. Arrisit animus iste Gratiis et amicitiae natus, qui tanto studio tuetur hominis eruditissimi innocentiam aduersus impudentissimos sycophantas. Arrisit denique te, hoc est absoluto veroque philosopho, digna moderatio: qua sic fortiter patrocinaris amico, ut a conuiciis in aduersarium temperes, magis reputans quid te quam quid illo dignum esset. Nam breuitati non perinde faueo, cum mihi licet occupatissimo perlectum opus famem sui reliquerit. Bene vale, doctissime Riti. Agrippinae. Anno M.D.XX ${ }^{22}$.

lengua hebrea, ¡qué impresionante es la que posee en filosofía! ¡qué impresionante en teología! ¡qué pureza de espíritu! ¡qué ansias de aprender! ¡qué candor por enseñar! ¡qué modestia al discutir! Si ya entonces el primer encuentro que tuve con este hombre en Pavía me agradó, mientras profesaba allí filosofía, ahora me agrada incluso más al poder tenerlo más cerca de mí. Él, en fin, me parece que se comporta como un auténtico israelita y que responde hermosamente a su apodo, porque todas sus intenciones, todo su cuidado, todo su tiempo libre y sus actividades lo dedica a las divinas escrituras. Digna es sin duda tal persona que tiene la suerte de disfrutar lo más posible de un tiempo libre tan honroso. No dejes de ponerme en buena disposición con el cardenal de Gurk, el mecenas más erudito de todos los eruditos. Cuídate bien. Amberes, 10 de marzo de 1516'.

${ }^{22}$ Cf. allen, IV 379. LB. 546. Trad.: 'Erasmo de Róterdam saluda a Paulus Ricius, filosofo consumadísimo. Tu opúsculo, eruditísimo Ricius, me ha vuelto más equitativo con quienes profesan la cábala, aunque anteriormente no era del todo hostil, pues considero que hay que disculpar como un defecto propio del ser humano el que alguien se consagre a tales afanes en los que no sólo ha consumido muchísimo tiempo, sino también confía plenamente en que está a la altura de ellos. Por otro lado, ¿quién puede soportar a los que persiguen con un rechazo tan penoso y tan obstinado lo que no entienden? Realmente a mi me gustó tu trabajo no por una sola razón. La erudición, que siempre te acompaña, aquí no me ha resultado nueva. Pero lo que en primer lugar 
Parece ser que Erasmo lo conoció en Pavía, donde Ricius profesaba filosofía. Rápidamente se despiertan en el holandés profundos sentimientos de afecto y admiración hacia la figura de este prácticamente desconocido personaje. A Erasmo, a quien ni la cábala ni el Talmud jamás habían hecho gracia (Cabala et Talmud, quicquid hoc est, meo animo numquam arrisit) ${ }^{23}$, sin embargo, cuando conoce la obra cabalística de Ricius y lee especialmente uno de sus escritos ( $l i$ bellus tuus), en el que defiende además la inocencia de un amigo contra indecentes calumniadores (aduersus impudentissimos sycophantas), le manifiesta que se ha vuelto más equitativo para con las materias de la cábala, aunque confiesa que anteriormente jamás le fue hostil.

Adam Melchior, siguiendo a Konrad Gesner ${ }^{24}$, afirma que es la In cabalistarum seu allegorizantium eruditionem isagoge (cf. infra opus $\mathrm{n}^{\mathrm{o}} 3$ ) el opúsculo que Erasmo elogia en este carta, opinión a la que parece sumarse Pierre Bayle ${ }^{25}$. Allen considera ${ }^{26}$ que se trata «probably» del «Apolegeticus aduersus obtrectatorem Cabalae sermo in which he replied to Hochstrat's Destructio Cabale, Cologne, Quentel, april 1519 ( $c f$. Ep. 1006, 74, 93 ${ }^{\mathrm{nn}}$ ), and defends Reuchlin against Hochstrat's censures» ${ }^{27}$. Allen supone que quizá Ricius mostró a Erasmo un texto manuscrito, porque no ha podido encontrar otra edición más reciente que la que lleva como título Apologetica in allegorizantium seu Cabaleorum

me agradó fue el candor y la claridad que pone las cosas ante los ojos de tal forma, que hasta a un ciego pueden resultar conspicuas. Me agradó ese modo de ser tuyo, por naturaleza complaciente y amistoso, que protege con tanto afán la inocencia de un hombre eruditísimo frente a desvergonzados calumniadores. Me agradó finalmente tu temple, del que eres merecedor por ser un filósofo completo y verdadero, temple con el que defiendes tan valerosamente al amigo, que de los insultos al adversario te abstienes pensando en lo que te conviene más a ti que a aquél. No aplaudo de la misma forma, pues, la brevedad, cuando a mí, aun estando siempre muy ocupado, la lectura completa de una obra no me ha dejado saciado. Cuídate bien, doctísimo Ricius. Colonia, año 1520'.

${ }^{23}$ Cf. Allen IV, Ep. 1033, Octuber 19, 1519, dirigida a Alberto de Brandemburgo. Cf. SeCRET, La kabbala cristiana, pág. 286; M. BAtaIllon, Erasmo y España (México-Madrid-Buenos Aires 1979) pág. 78. Cf. GuNDERSHEIMER, «Erasmus, Humanism and the Christian Cabala», págs. 38-52.

${ }^{24}$ Cf. infra las notas 43,45 y 48.

${ }^{25}$ Cf. Dictionnaire historique et critique (Amsterdam 1697) 4 parties en 2 vols. in-folio, vol. IV, pág. 54. Bayle dice exactamente: «Ricius lui envoia son Traité de la Cabale et en reçut un remerciment qui lui est tres-glorieux; car il fait connoître que ce prosélyte, soutenant la cause d'un de ses amis cruellement décchiré par la calomnie, n'étoit point sorti des bornes de la modération, et n'avoit dit d'injures».

${ }^{26}$ Cf. Allen IV, Ep. 1160, págs. 379.

${ }^{27}$ Johannes Hochtrat escribió ciertamente una Apologia et Cabalae Destructio, del que GESNER dice en su Bibliotheca Universalis (pág. 426): «audio hominem fuisse indoctum et improbissimum aemulum optimi uiri Ioan. Capnionis (= Reuchlin). 
dogma oratio, Núrenberg 1523, y dedicada a Adriano VI". No existe, en efecto, una edición anterior a 1520 de dicha Apologetica ... oratio (cf. infra opus $\mathrm{n}^{\circ} 15$ ), por lo que la posibilidad más plausible es, en nuestra opinión, que el libellus cabalístico aludido por Erasmo sea la In cabalistarum seu allegorizantium eruditionem isagoge de 1515 (cf. infra opus $\mathrm{n}^{\circ}$ 3), edición que incluye una Epistola defensoria contra obtrectatorem Cabalae ad Venerabilem D. Doctorem Stambler, inexistente en la edición de 1510. Gundersheimer, siguiendo a Allen, considera también que en la mencionada epístola erasmiana se alude a la defensa que Ricius realiza de Reuchlin como cabalista, es decir, a la Apologetica ... oratio «which Erasmus may have seen in manuscript in $1519 »{ }^{28}$. No obstante, si leemos detenidamente la misiva, en ella sólo se hace referencia a un libellus de contenido cabalístico y a algunos rasgos del carácter del converso alemán, entre ellos el que se refiere a su acendrado afán por defender a los amigos, pero nada más. Otra opinión bien diversa es la expresada por el investigador Secret, quien afirma que el libellus al que alude Erasmo en su epístola es la traducción que hizo en 1516 Ricius de la Porta Lucis de Chicatilla, pero no parece apropiado que el humanista holandés utilice el posesivo tuus para aludir a un opúsculo no original del converso.

Otras breves alusiones de Erasmo al converso alemán se localizan fundamentalmente en diversas cartas dirigidas al humanista Willibald Pirckheimer (año 1525), en las que generalmente le ruega que salude de su parte a Durero y a Ricius, debiendo formar los cuatro, al parecer, un grupo bien avenido. Una carta dirigida a Viglio Zuichemo (Epist. 372: Patauium, 14 Maii, anno 1533), es la referencia última que hallamos en el epistolario del humanista holandés: «Ricii Libros cupide legam, si prodierint», donde Erasmo, además de confesar su enorme interés por las obras de Ricius, insinúa cierta dificultad de acceso a las mismas, tanto más extraña cuanto que en el año 1533 habían salido a la luz (prodeo) prácticamente todos sus escritos (véase infra, en el apartado 3, el catálogo de obras del converso).

1.1.2. La siguiente referencia contemporánea la he localizado en el De arte cabalistica libri III Leoni X dicati de Johann Reuchlin, publicada en 1517, en los que introduce tres personajes: Filolao el joven, filósofo pitagórico, Marrano, mahometano converso, y el judío Simón, quien expone la kabbala en los libros I y III, siendo Filolao quien expone la filosofía pitagórica en el II. Tras una definición de la Cábala por parte del joven griego como una «teología simbólica» al modo pitagórico, Simón menciona a Paulus Ricius (y su condición de converso) junto al conde la Concordia en el libro III como los primeros que publicaron

${ }^{28} C f$. Gundersheimer, «Erasmus, Humanism and the Christian Cabala», pág. 49. 
en lengua latina los misterios cabalísticos, aunque lo que transmitieron no fue suficientemente entendido por los doctos de la lengua latina:

Ac ille [Philolaeus]: Certe quidem. Enimuero nunc eius disciplinae intrauimus nauim et mox in ipsa prora sentimus, Cabalam aliud nihil esse nisi (ut Pythagorice loquar) symbolicam theologiam in qua non modo litterae ac nomina sunt rerum signa, uerum res etiam rerum. Quo animaduertimus Pythagorae philosophiam fere omnem esse a Cabalaeis ortam, qui pari modo symbolicum tradendi morem ad graecos transtulit, quin egoipse quoque cum sodali hoc meo te uehementer oro ut dicendo ac potius docendo pergas.

Tum Simon: Non mihi tam iactantiae usurpauerim, ut docere uos audeam, nec bene tutum fuerit in re tam perplexa, nondum extraneis cognita, praesertim Romane doctis, praeter admodum pauca quae annis superioribus Ioannes Picus Mirandulae Comes et Paulus Ricius quondam noster ediderunt, etiam usque ad hodiernum latinis non satis intellecta ${ }^{29}$.

Poco después, el mismo Simón, al introducir el tema de las diez enumeraciones que los Cabalei llaman «sefirot», menciona las obras de Ricius como de consulta esencial en el tema, en especial su traducción de la Porta Lucis ( $c f$. infra opus $\mathrm{n}^{\mathrm{o}}$ 9) y la Isagoge in Cabalam (cf. infra opus $\mathrm{n}^{\mathrm{o}} 3$ ):

[...] quae facile nunc ut arbitror de libro Cabalistico compendii Portae lucis, quem Paulus Ricius, uir egregie doctus, quondam ex nostris unus, nunc christianus, ex Rabi quodam Castiliensi collegit, et de Isagogis quas scripsit in Cabalam discere potestis ${ }^{30}$.

${ }^{29}$ Cf. F. SECREt (ed.), La Kabbale. De arte cabalistica. Johann Reuchlin. Introduction, tr duction, notes par... Nouvelle ed. augm. de quatre index \& du fac-similé de l'ed. originale latine (Hagenau 1517) (Paris 1973), ff. [LIv]-LIIr. Trad.: 'Filolao: Es cierto. Pero una vez embarcados en estos estudios, siento que hemos llegado al fondo de la cuestión, esto es, que la Cábala no es otra cosa que (para decirlo al modo pitagórico) una teología simbólica en la que no sólo las letras y los nombres son signos de lo que nos rodea, sino también son la realidad misma. Por esto advertimos que casi toda la filosofía de Pitágoras surgió de los cabalistas, quien de igual modo transmitió a los griegos la costumbre de la tradición simbólica. Es más, yo mismo te ruego encarecidamente que con nuestro compañero aquí presente continúes hablando y sobre todo enseñándonos. Simón: Yo no me arrogaría tanta jactancia como para atreverme a enseñaros, ni me hallaría tan pertrechado en cuestión tan compleja, aún desconocida a los extraños, en particular a los doctos de la lengua latina, excepto lo poquísimo que en años anteriores Jean Pico della Mirandola y Paulus Ricius, antaño de los nuestros, editaron, tampoco muy entendido por los latinos hasta el día de hoy'.

${ }^{30}$ Cf. SECRET (ed.), La Kabbale, f. LXIIr. Trad.: 'Lo que fácilmente ahora, a mi juicio, podéis aprender por el libro Cabalístico compendiado de la Puerta de la Luz, que Paulus Ricius, varón docto por encima de muchos, antaño uno de los nuestros, ahora cristiano, realizó a partir de la obra de cierto rabino castellano, y por la Isagoge que escribió a la Cábala'. 
1.1.3. Se conservan asimismo dos cartas de JoHANNEs EcK (1486 -1543) en las que el teólogo alemán menciona a Ricius: una con fecha de 27/03/1519 dirigida a Andreas Henlein ${ }^{31}$ (Ad D. Pauli Ritii Israelitae de anima coeli examina) y otra con fecha de 13/11/1519 a Maximiliam von Zevenberg ${ }^{32}$. En la primera Eck se queja de las amargas críticas de noster amicus Ricius contenidas en su De anima coeli examina a propósito de su comentario a la física aristotélica ${ }^{33}$ :

Reverendo Patri d. Andreae Episcopo in pontificalibus reverendissimi Episcopi Bambergensis Vicario Eckius S. D. Post commentarios dialectices et physice auscultationis absolutos, Reverende Pater, dum iam sub praelo essent commentarij in secundam partem physices, ultra umbilicum etiam ducti, vidi Auguste, dum Reverendissimum Cardinalem Gurcensem adirem, excusum amici nostri d. Pauli Ricii de anima coeli compendium adversus me exaratum, ubi in ipso vestibulo amariuscule me taxat: quod suae sententiae repugnaram plus etiam aceti addens quam amicicia nostra merebatur. At quia vir est bonus ac honestus et non vulgaris eruditionis sive in arena sua medica aut in philosophia, etsi vis etiam Theologia, versetur nolui calamum contra eum exasperare, verum salva amicicia, liceat nobis hoc loco de anima coeli dissentire [...].

Pierre Bayle (1647-1706) recoge en su Dictionnaire ${ }^{34}$ esta disputa con el célebre Johannes Eck a propósito de la cuestión de si los cielos tienen alma. El filósofo

${ }^{31}$ Benedictino, profesor y prorrector en 1517 en Ingolstadt. Desde septiembre de 1517 obispo auxiliar y pastor en San Martín de Bamberg. Fallecido en 1542. Cf. J. KIst, Die Matrikel Bistums Bamberg 1400-1556 (Würzburg 1965), n. ${ }^{\circ} 2618 \mathrm{e}$.

${ }^{32}$ Cf. V. PFNür (coord.), Johannes Eck (1486 -1543). Briefwechsel), edición electrónica de la correspondencia de Eck con traducción y comentarios en alemán localizada en http://ivv7srv15. uni-muenster.de/mnkg/pfnuer/(última actualización: 15-I-2008

${ }^{33}$ Ediciones del comentario a la física aristotélica realizadas por Eck, según referencias del ed tor alemán de la carta dirigida a Henlein son EcK, Ad D. Pauli Ritii Israelitae de anima coeli examina. Augsburg, s.l.a. = Augsburg: $1519=$ MetZleR, S. LXXIX Nr. 21 (Westfalen $1930=$ Corpus Catholicorum Bd. 16). Trad.: 'Al Reverendo Padre D. Andreas, obispo vicario en las cuestiones pontificales del reverendísimo obispo de Bamberg, Eck envía un saludo. Después de completar mis comentarios sobre la dialéctica y sobre la investigación de la naturaleza, Reverendo Padre, y mientras mis comentarios sobre la segunda parte de la naturaleza estaban en prensa, también concluídos del todo, vi en Ausburg, durate mi visita al Reverendísimo Cardenal de Gurk, un compendio impreso por nuestro amigo D. Paulus Ricius Sobre el alma del cielo. Este escrito iba dirigido contra mí, en el que desde el principio me censura con acritud, porque yo había contradicho sus puntos de vista con una acidez impropia de nuestra amistad. Pero como es un hombre bienintencionado y honesto, carente de vulgar erudición tanto en su ejercicio de la medicina como de la filosofía, y, si se quiere, también está versado en Teología, no he querido afilar mi pluma contra él. Pero salvada nuestra amistad, permítaseme disentir en esta cuestión sobre el alma del cielo [...]'.

\footnotetext{
${ }^{34}$ Cf. Dictionnaire historique et critique (Amsterdam 1697), vol. IV, pág. 54.
} 
francés menciona la opinión del también filósofo Gisbertus Voetius (Desperata causa Papatus, 1635), quien se extraña de que «Paulus Ritius», cuando transmitió su idea del alma o animación de los cielos y su cabalística Aritmancia a través de las diez enumeraciones, promovió en no poca medida los principios de la magia en sus comentarios al libro de R. Yosef Chicatilla que se llama Porta Lucis ( $\breve{a}$ 'aré Orá) y, sin embargo, sus libros De caelesti agricultura fueron aprobados con gran elogio por la Academia Teológica de Bolonia, de Padua, de Ferrara, de Pavía. Bayle sitúa a Ricius en la base de la idea científica de si el motor inmediato de las esferas celestes es un alma propiamente dicha (teoría de la existencia de Inteligencias motrices y de la hipótesis de los torbellinos), y menciona los nombres de Copérnico, Jean Eck, Claude Despence, el P. Daniel, Le Clerc y Newton en la estela de estas disputas acerca de si los cielos tienen alma ${ }^{35}$.

En la segunda misiva dirigida ocho meses después a Maximiliano, barón de Zevenberg y orator del emperador Carlos V, Eck deja traslucir cierta inquina hacia el médico alemán (tilda de nugae los libros de Ricius), cuyas objeciones a su obra se propone rebatir ${ }^{36}$ :

[...] Ad haec omnia rara accedit eruditio et singularis, quam frequens indies auget lectio selectorum librorum praetiosa suppellex; quae se comitem tibi more Alexandri Magni per varia associat itinera et adeo quidem legendi cupidus es, praeclarissime Maximiliane, ut nugas etiam Pauli Ritii ex Iudaismo conversi legere non dedignatus fueris, quod etsi pro acumine ingenii tui et syncera doctrina arbitrer facile te deprehendisse, quam ille caecutiat et tenebras animasticas nobis offundat. Volui tamen, ut reliquus philosophorum ac Theologorum coetus per te intelligat me iustissime motum ad obiecta Riciana diluenda, quibus praeter angelos et homines aliam comminiscitur creaturam rationabilem [...].

${ }^{35}$ En el estudio decimonónico de Theodor Wiedemann sobre Johannes Eck (Dr. Johann Eck. Professor der Theologie an der Universität Ingolstadt. Regensburg. Regensburg 1865) encontramos en las págs. 335-344 un capítulo dedicado a «Eck und Paulus Ritius».

${ }^{36}$ EcK, Ad generosum D. Maximilianum ex baronibus Zwevenbergiis. Inclitissimi Caroli V. Romanorum et Hispaniarum regis oratorem Ioan. Eckii defensio adversus invectiones Ritianas. S.1.a. [1519], Widmung Ecks = METZLER Nr 31 [F 010.d]. Trad.: 'A todo esto se añade tu inusual erudición y el precioso bagaje de una singular capacidad de leer libros selectos que aumenta cada día más, y que te acompaña como a Alejandro Magno en viajes diversos. Y tu avidez de leer es tal, ilustrísimo Maximiliano, que incluso las bagatelas de Paulus Ricius, judío converso, no has desdeñado leer, aunque por la agudeza de tu ingenio y tu doctrina íntegra me resulta fácil pensar que tú has descubierto cuán ciego está aquél, y cómo extiende en derredor nuestro tinieblas sobre el alma. Quise, sin embargo, que el resto del grupo de filósofos y teólogos entendiese a través de ti que yo me he movido en justicia para refutar las objeciones de Ricius, quien además de los ángeles y los seres humanos imagina otra criatura dotada de razón'. 
1.1.4. En la edición del libro de UlRich von Hutten (1488-1523), De guaiaci medicina et morbo Gallico liber vnus (Parisiis 1519) ${ }^{37}$ encontramos en los ff. K-K.ii un intercambio epistolar entre los dos médicos alemanes Paulus Ricius medicus Vlrico de Hutten equi(ti) salutem (Augustae, IIII Idus Novembris) y Vlrichus de Hutten eques Germanus Paulo Ricio caesaria medicina salutem (Idibus Nouembris), donde no se incluyen referencias significativas a las obras de Ricius; pero hemos de advertir que von Hutten escribió, entre otras obras, el poema satírico Triumphus Capnionis [= Reuchlin] en 1514, y fue el autor principal de la segunda parte de las satíricas Epistolae Obscurorum Virorum (1515-1517) contra los enemigos de Reuchlin, donde lanza a los aires sus carcajadas blasfemas contra los teólogos, contra los frailes y contra Roma, lo que nos ayuda a perfilar los rasgos de un personaje hasta el momento muy difuminados.

1.1.5. En España el eco de la obra de Ricius lo encontramos relativamente pronto en las Paradoxae quaestiones numero decem (In alma Salmanticensium Academia, 1538) ${ }^{38}$ de Pedro Ciruelo (Daroca 1470 - Salamanca 1548). La Quaestio decima hebraica intitulada De cabala \& magia Iudeorum in enarranda diuina biblia está dirigida a los estudiantes de la universidad salmantina. Se denomina Paradoxa porque casi toda la exposición irá contra la común opinión de los doctores, para la cual seguirá el método escolástico y una división en tres partes en contestación a esta pregunta: ¿es útil a los teólogos la cábala para comprender mejor las Sagradas Escrituras y los misterios de la fe católica?

Menciona en una única ocasión a Paulus Ricius haciéndole erróneamente preceptor y educador de Pico della Mirandola ${ }^{39}$, lo que parece evidenciar su conocimiento superficial del personaje ${ }^{40}$ :

${ }^{37}$ Cf. Biblioteca Digital e Histórica-Fondo Antiguo de la UCM (Sign. BH MED 1829). Se co serva también una carta de Erasmo a Hutten de 23 de julio de 1519, portadora del famoso retrato de Tomás Moro, la primera «biografía» en miniatura del escritor inglés ( $c f$. A. de SiLVA, Un hombre para todas las horas. La correspondencia de Tomás Moro, Madrid 1998, págs. 141-152).

${ }^{38}$ Paradoxae quaestiones numero decem / ex officina Magistri Petri Cirueli Darocensis nunc depromptae. In alma Salmanticensium Achademia: [Gundisalvus de Castañeda], 1538, [64] h.; $4^{\circ}$. Se conservan ejemplares en las B[ibliotecas] U[niversitarias] de Salamanca, Valencia, Complutense y BNE.

${ }^{39}$ Pico fue iniciado en la cábala a través de las enseñanzas en hebreo que recibiera de judíos conversos, como Flavio Mitrídates, Pablo de Heredia y Elía de Médigo, portadores de esta tradición, según había sido desarrollada en el siglo XIII en suelo hispánico. Durante la Edad Media algunos conversos habían argumentado los dogmas cristianos mediante el Antiguo Testamento, cf. G. Scholem, Les origines de la Kabbale (Paris 1966).

${ }^{40} C f$. F. SeCret, «Pedro Ciruelo: Critique de la kabbale et de son usage par les chrétiens», Sef 19 (1959), págs. 59-60. 
De his scripsit rabi Joseph Castiliensis in sua Isagoge ad Cabalam, et alius rabi Joseph ben Carnitol ${ }^{41}$ in libro Portarum Justitiae et Paulus Ricius ex Judaeis factus christianus (hic fuit Johannis Pici Mirandulae preceptor atque institutor) qui in suo compendio cabalistico Porta Lucis dicto de his enumerationibus dicit quod in eas reducitur tota scripturarum veteris legis continentia et addit quod Ensoph sit alpha et omega sive principium et finis ${ }^{42}$.

\subsection{Referencias bio-bibliográficas: el catálogo de Gesner (1545)}

1.2.1. Apenas tres o cuatro años después de la fecha que los estudiosos modernos de Ricius suelen dar de su muerte, se publica en la Biblioteca Universalis (Zürich 1545) ${ }^{43}$ del humanista y médico KonRAD Gesner (1516-1565) el primer listado de las obras (con lugares -Alemania, Ausgburgo- y fechas de edición -de 1515 a 1541-, así como un breve extracto del prefacio de aquellas de mayor relevancia) del Israelita (uir doctissimus, ad Christianam fidem conuersus et Maximiliani Caesaris physicus): un extenso catálogo con información precisa de cada uno de los libros.

Gesner destaca en primer lugar, por delante de todos los demás, uno de los opúsculos del converso:

[1] Statera prudentum ['Balanza de los prudentes'], libro impreso en Alemania en 1532 [en $8^{\circ}$, en 6 pliegos y medio] Está dividido en 28 capítulos o teoremas, enumerados en el primer cuaderno de cuatro pliegos: están todas las cuestiones teológicas sobre Moisés y la ley, por un lado, sobre Cristo y el evangelio, por otro.

Del mismo autor, refiere Gesner a continuación, existen diversos opúsculos impresos en Augsburg, por Johann Millar, en 1515 [en 4º , en 34 pliegos] (son obviadas, como veremos, las ediciones impresas en Italia):

${ }^{41} \mathrm{He}$ corregido la forma «Cornicol» del texto editado por Secret ( $c f$. nota anterior).

42 Trad.: 'Sobre estas cuestiones escribió el rabí Yosef Chicatilla en su Isagoge a la Cábala, también otro rabí llamado Joseph ben Carnitol en el libro Las puertas de la Justicia y Paulus Ricius, judío converso (preceptor y maestro de Pico della Mirandola), quien en su compendio cabalístico llamado Puerta de la luz alude a estas enumeraciones, diciendo que en ellas incluye todo lo que se contiene en el Antiguo Testamento y añade que Ensoph es el alpha y el omega, es decir, el principio y el fin'.

${ }^{43}$ Bibliotheca vniuersalis siue Catalogus omnium scriptorum locupletissimus, in tribus li guis, Latina, Graeca, \& Hebraica ... / authore Conrado Gesnero... (Tiguri: Apud Christophorum Froschouerum, 1545) págs. 1120-1122 [edición digitalizada por la BU Valencia: (BH Z-12/145)]. La letra en cursiva, la numeración de las obras y la traducción del catálogo de Gesner son mías. 
[2] De sexcentum et tredecim mosaice sanctionis edictis ['Sobre los seiscientos trece mandamientos de la ley mosaica o Pentateuco'], cuya primera parte contiene los mandatos negativos y la segunda los positivos. Se añade una breve interpretación al final de cada capítulo.

[3] Philosophica, prophetica ac thalmudistica pro Christiana ueritate tuenda cum iuniori Hebraeorum synagoga, mirabili ingenii acumine disputatio ['Disputa filosófica, profética y talmúdica en defensa de la verdad cristiana, con la sinagoga más joven de los hebreos, de admirable agudeza de ingenio'], tratado dividido en tres partes, cuyos capítulos se indexan desde el inicio ${ }^{44}$.

[4] In cabalistarum seu allegorizantium eruditionem Isagoge ['Isagoge a la erudición de los cabalistas o intérpretes alegóricos'], le acompaña una epístola contra la del presbítero Stephanus, detractor de la cábala ${ }^{45}$.

[5] De novem doctrinarum ordinibus et totius peripatetici dogmatis nexu compendium ['Compendio sobre los nueve órdenes de las doctrinas y la conexión de todo el dogma peripatético'], donde se exponen las palabras de Galeno desde el inicio de su Ars parva, qué cosa sea la doctrina, qué el orden, cuáles las leyes inexorables y la eficacia del orden, división del orden en la doctrina.

[6] Oratio resolutiua de triplici ordine doctrinae ["Discurso explicativo del triple orden de la doctrina"].

[7] Conclusiones, con las que poder comprender el triple orden de la doctrina que Aristóteles puso en práctica y el nexo de todo su dogma.

Siguiendo de nuevo el hilo de las palabras de Gesner, todas las obras hasta aquí enumeradas (excepto la Statera prudentum y la Disputatio contra Iudaeos (scil.[3]) y otras que a continuación añade, han sido impresas en Ausgburgo en el año 1541 [in fol., 107 pliegos].

[8] De coelesti agricultura libri 4 ['Sobre la agricultura celeste' en cuatro libros], dedicados al césar Carlos V y su hermano Fernando. El argumento está tomado de la

\footnotetext{
${ }^{44}$ Incluye un extracto del prefacio del autor, que coincide con el texto al que hace referencia la nota 62 .

${ }^{45}$ Añade un extracto del prefacio donde se describe el contenido de los dos bloques fund mentales de la obra (Duo hoc opus complectitur).
} 
metáfora sobre las semillas que se lee en Mateo 3, como el propio autor explica ampliamente en el prefacio. El primer libro está dedicado a los filósofos que no creen en nada salvo en lo que la razón o los sentidos les dictan. El segundo, a la sinagoga de judíos que, por una parte, aceptan algunos fundamentos de la ley, pero rechazan otros. El tercero, a los que son completamente fieles a su devoción que veneran y cultivan, pero en algunas cuestiones se desvían de la recta senda del conocimiento. El cuarto, a la mayoría de los fieles que creen solícita y piadosamente en lo que se refiere a la fe en la verdad; sin embargo, practican sus creencias con cierta ignorancia y negligencia. Los filósofos se asemejan a la semilla que cae en el camino y se pisotea; los judíos, a la que cae en las piedras; los herejes, en las espinas; los fieles, en la tierra fecunda, etc.

[9] De communi Sacramentorum ratione, ['Sobre la explicación común de los Sacramentos'] un sermón al que hay que prestar atención, señala Gesner.

[10] De archana Dei prouidentia, commentariolum in Psalmum «Beatus uir» ['Sobre la arcana providencia de Dios, breve comentario al salmo Beatus vir'].

[11] De anima coeli, iuxta sanctorum et philosophorum traditionem compendium ['Compendio sobre el alma del cielo, según transmiten los santos y los filósofos'].

[12] De ratione et partibus prooemii secundum rhetores ['Sobre la explicación y las partes del proemio según los rétores'] en 4 capítulos, formado por tres pliegos en $4^{\circ}$.

[13] De modo indagandi statuendique cuiuslibet scientiae subiectum ['Sobre el modo de indagar y organizar cualquier cosa que caiga bajo el dominio del conocimiento'].

[14] In uirulentam immanissimamque Turcarum rabiem, ad principes, magistratus populosque Germaniae, docta et feruida oratio ['Discurso docto y apasionado contra la virulenta y muy monstruosa violencia de los turcos, dirigido a los príncipes, magistrados y pueblos de Alemania'].

[15] Ex Talmudaeorum codice excerpta farrago ['Compilación extractada del códice de los talmudistas'] a petición del césar Maximiliano, casi 10 pliegos $^{46}$.

Gesner, pues, nos ofrece el catálogo de las obras de Ricius más extenso y completo hasta el momento ${ }^{47}$, obviado por los modernos estudiosos del hebraísta, que nos servirá de base para realizar el que en este trabajo presentamos.

${ }^{46}$ Del prefacio de dicha obra destaca Gesner unas palabras: «Sobre el compendio talmúdico, 11 mado Mišná (dicto Miscna), en torno al cual giran el conjunto de los estudios del Talmud y todo su andamiaje, he decidido sacar a la luz algo y arrancar de aquellos cual flor una extensa glosa, contentándome simplemente con haber extraído al menos unas pocas cláusulas y capítulos de los temas [...]».

${ }^{47}$ Exactamente las mismas quince obras se recogen en el De scriptoribus ecclesiasticis siue p[er] scripta illustribus in Ecclesia viris, cum appendicibus duabus ... liber vnus, de Johannes Trithemius (ex officina Petri Quentel), publicado pocos años después (Coloniae 1546). 
1.2.2. Siguiendo con nuestra búsqueda y localización de fuentes contemporáneas, hemos de llegar al siglo XVII, para encontrar en el volumen II de las Vitae Germanorum (1620), dedicado a los medici, de ADAm MELCHIOR, una breve semblanza biográfica de Paulus Ricius. Se sitúa expresamente en Alemania su lugar de nacimiento (natus in Germania) y su floruit ca. 1514, se menciona su temprana conversión al cristianismo, su afición por los temas de filosofía natural, su estancia en Italia donde enseñó filosofía, su nombramiento como médico del emperador Maximiliano, el elogio de Erasmo y, finalmente, un catálogo de sus obras ( $\sin$ fechas de edición) en los siguientes términos: ${ }^{48}$

Edidit non pauca, quibus et Iudaeorum refractariorum technas detexit, et rem literariam promovit. Scripsit enim:

[1] De sexcentis et tredecim Mosaicae sanctionis seu pentateuchi dictis (sic) librum, cuius prior pars prohibentia, posterior affirmantia praecepta continet, singulis brevi interpretatione subiuncta.

[2] Philosophiam, propheticam ac Thalmudisticam pro veritate Christiana tuenda, cum iuniori Hebraeorum synagoga, disputationem mirabili ingenii acumine, in tres diuisam tractatus.

[3] Excerpsit ad petitionem iussumue Maximiliani Caesaris farraginem ex Thalmudi codice.

[4] Confecit et Isagogen in Caballistarum doctrinam, quam commendat Erasmus *alicubi, contra Stephani presbyteri, cabalae obtrectatoris epistolam [in marg.: lib. 13. epistol.]

[5] Item de novem doctrinarum ordinibus et totius Peripatetici dogmatis nexu compendium, quo exponuntur uerba Galeni ab initio artis paruae, quid doctrina, quid ordo, quae ordinis necessitas et praestantia, quotuplex in doctrina ordo, et

[6] Orationem resolutivam de triplici ordine doctrinae.

[7] Edidit conclusiones, quibus Aristotelem triplicem doctrinae ordinem exercuisse et totius cuius dogmatis nexum diiudicare poteris.

[8] Praeterea stateram prudentum, et libros quatuor de caelesti agricultura; et quaedam alia quae in bibliothecis indicantur.

${ }^{48}$ Vitae Germanorum medicorum: qui seculo superiori, et quod excurrit, claruerunt. conge tae. Ad annum usque cIc Icc XX. Deductae a Melchiore Adamo. Cum indice triplici: personarum gemino, tertio rerum. Haidelbergae, Impensis heredum Jonae Rosae, Excudit Johannes Georgius Geyder, Acad. Typogr. Anno M. DC. XX, págs. 9-10. Las letras en cursiva aparecen en el texto original. La numeración entre corchetes es mía. 
La fuente de Melchior, palpablemente extractada, es, sin lugar a dudas, Gesner, citado al final del capítulo: Caetera habent Pantal(eo) 1. 3 Prosopographiae ${ }^{49}$, Erasmus in epistolis, Gesnerus, alii.

\section{Obra de Paulus Ricius}

Consultados y contrastados, pues, los datos que nos suministran las fuentes aportadas en este estudio y los catálogos de diversas bibliotecas europeas ${ }^{50}$, Ricius escribió las siguientes obras, editadas en dos lugares de imprenta fundamentales, Papia (Pavía) de 1507 hasta 1510 y sus reediciones y ediciones en Augusta Vindelicorum (Augsburgo) desde 1514 a 1541:

1. Compendium quo mirifico acumine (Judeorum insipientiae reffellendo calumnias) apostolicam veritatem: Ratione, Prophetice, Talmudistice, Cabalistice plane confirmat ac judaeorum fidei tollit repugnantiam. Insuper quarti tractatus exordio triplicem doctrinae ordinem, a Galeno obumbrante traditum perpulchre edit in lucem... Impressum Papie, per magistrum Jacob de Burgofrancho, 1507 (reed. 1511).

2. Aphoristicae in cabalistarum eruditionem cum digressionibus isagogae. Ejusdem de modo inveniendi subjecta doctrinarum et ordinem conclusiones lepidaque oratio. Magnanimo et preclaro Stephano Ricio Georgius Pharelius advocatus S. et felicitatem. Impressum Papie, per magistrum Bernardinum de Garaldis, anno Domini 1509.

3. In cabalistarum seu allegorizantium eruditionem Isagoge, Papiae, per Magistrum Jacob Burgofrancho 1510; Augustae Vindelicorum 1515.

4. De novem doctrinarum ordinibus et totius perypatetici dogmatis nexu compendium, conclusiones atque oratio, Pavia per Magistrum Jacob Burgofrancho 1510; Augustae Vindelicorum 1515.

${ }^{49}$ Se trata del historiador alemán Heinrich (Henricus) Pantaleon (1522-1595) cuya vida y e tensa obra es recogida por A. Melchior (op. cit. s.u. págs. 396-403). El título completo de la obra es Prosopographia heroum atque illustrium virorum totius Germaniae, pars prima [-tertia]. [...] Basileae : Nicolai Brylingeri, 1565-1566. [3 t. en 1 vol. in- $2^{\circ}$ ]. Sólo por cita indirecta hemos localizado la referencia a Ricius en vol. III, pág. 151 (no añade datos nuevos a los aportados por Melchior).

${ }^{50}$ En la BNE sólo aparece catalogada la ${ }^{\circ} 9$ [R/41057]. El Catálogo Colectivo del Patrimonio Bibliográfico Español registra nueve obras en nuestras bibliotecas, públicas y privadas. El Catalogue collectif de France (CCFr) nos ofrece un listado de 25 ediciones, más ocho obras en las que aparece Ricius de forma secundaria (en Gallica puede consultarse la Isagoge de 1515 y la Philosophica... disputatio de 1514). Cf. et el catálogo de las bibliotecas y centros de digitalización de Munich [Münchener Digitalisierungszentrum (MDZ)], de la Bayerischen Staatsbibliothek (BSB), de la Austrian Literatura Online (ALO) y de la Biblioteca Universitaria de Innsbruck. 
5. De sexcentum et tredecim mosaice sanctionis edictis. Papiae, per magisrum Jacob Burgofranco, 1510; Augsburg, Johann Miller, 1515.

6. Hoc opere contenta. De proemio et eius partibus questio. De formali ratione subiecti compendium. Averois in phisico auditu proemium emendatum. Praeclara admodum et omnibus aliis in hac scientia operibus resolutior Averois in quattuor de coeli et mundo paraphrasis fideli et clara verborum serie iam dudum de hebraicis latebris in latinum splendorem conversa. Averois in dudodecimo metaphisicae proemium quoque de hebraico decerptum exemplari. Milano, Leonardus de Vegii $1511^{51}$.

7. In Apostolorum Simbolvm ... oratoris philosophi et theologi ocvlatissimi a priori demonstratiuus dialogus, Augustae Vindelicae 1514; Augusta Vindelicorum 1515; In Apostolorum simbolum juxta peripateticorum dogma dialogus. Papie, per Bernardinum de Garaldis, 1517, 1519. Contiene una epistola prefatoria de Pietro Pomponazzi (Petrus Pomponetius).

8. Philosophica, prophetica ac talmudistica, pro christiana veritate tuenda cum iuniori Haebreorum synagoga mirabili ingenii acumine disputatio, Augusta Vindelicorum 1514.

9. Portae lucis: haec est porta Tetragrammaton, iusti intrabunt per eam [traducción latina del Ša aré Orá de Yosef b. Abraham Chicatilla], Augusta Vindelicorum 1516.

10. In psalmum Beatus uir commentariolum, Augusta Vindelicorum, Sigismund Grimm \& Marcus Wirsung, 1519.

11. De communi ratione Sacramentorum sedula lectione dignus sermo, Augusta Vindelicorum 1519.

12. De anima coeli compendium. Responsio ad interrogationes de nomine Tetragrammaton, Augusta Vindelicorum 1519.

13. Apologetica ad Eckiana responsa narratio, Augusta Vindelicorum 1519, $1520^{52}$.

${ }^{51}$ Cf. Index Aureliensis I/2 (Geneve 1962), pág. 368, nº 109.804, cit. en I. Zinguer (ed.), L'Hébreu au temps de la Renaissance: ouvrage collectif (Leiden 1992), pág. 113, que señala la rareza de dicha edición de 1511 («sono noti soli sei esemplari»), cuyo ejemplar consultado se encuentra en la Bayerische Staatsbibliothek [Sign.: 2 A.gr.b. 115]. Sobre las sucesivas ediciones $c f$. F. E. Cranz, A Bibliography of Aristotle editions 1501-1600 (Baden-Baden 1971), pág. 235.

${ }^{52}$ Johannes Eck (1486 - 1543) escribió a su vez, como apuntamos, una Ad D. Pauli Ricii Israelitae de anima coeli examina responsio. Eckij artium. iuris \& theologiae doctoris amica responsio (Augsburg 1519). 
14. Talmudica nouissime in latinu[m] versa periocunda co[m]mentariola / Naturalia \& prophetica de Anima coeli omni attentione digna aduersus Eckium examina. Lepida \& liter[a]e vndiq[ue] concinna in psalmu[m] beatus vir meditatio. Concisa \& arcana de modo orandi in nomine tetragrammaton responsio. Augustae Vindelicorum, In officina excusoria Sigismundi Grimm medici et Marci Wirsung, 1519 [in $\left.4^{\circ}\right]^{53}$.

15. Apologetica et spirituali eruditione plena, ad pontificem Maximum in allegorizantium dogma Oratio, Nurimberga 1523, Augusta Vindelicorum 1525.

16. Ad principes, magistratus populosque Germaniae, in Spirensi conventu oratio, Speyer u. Wien 1529, Ausgutae Vindelicorum 1530.

17. Conclusiones quas Paulus Ricius israhelita ratione Aristotelis Aueroisque dogmate protegere pollicetur, [s.1., s.n., s.a.] ${ }^{54}$.

18. Statera Prudentvm ... Christo Nazareno regni coelorum Duci, Tribunis, ante signanis, et cohortibus crucis compendiarum, et omni attentione dignum hoc P. R. opus desudat, Augusta Vindelicorum $1532^{55}$.

19. De coelesti agricultura, Augusta Vindelicorum, per Henricum Stayner, 1541 .

En la última obra de esta lista, dedicada al emperador Carlos $\mathrm{V}$ y a su hermano Fernando, Ricius funde sus principales tratados anteriormente publicados, entre ellos, la In Cabalam Isagoge, que atraerá la atención del jesuita Athanasius Kircher. No he podido localizar ningún ejemplar de esta obra en España, salvo en la edición que Pistorius hizo en 1587 junto con otras obras, una antología de textos cabalísticos ${ }^{56}$, que ha llegado a ser considerada como la «Biblia de la cábala cristiana». Contiene el De verbo mirifico y

${ }^{53}$ Existen sendas ediciones en la Biblioteca General Universitaria de Sevilla y en la de Navarra.

${ }^{54}$ Según el Catálogo Colectivo del Patrimonio Bibliográfico Español, fue impreso antes de febrero de 1531, según an. ms. de compra de Hernando Colón en el ejemplar de la Biblioteca Capitular y Colombina de Sevilla, Sign. top. 4-5-10(5).

${ }^{55}$ El título de la penúltima obra de Ricius está sacado de Proverbios XVI, 2, escrito para tratar de incitar a un acuerdo a católicos y reformados, que lo enfrentó violentamente con el obispo de Viena Joannes Faber, quien censuró el libro. También lo condenó en Ratisbona (1532) Jerónimo Aleandro, siendo esta una de las causas por las que se incluyeron las obras de Ricius en el Índice. Cf. SeCret, La kabbala cristiana, pág. 173; Roling, «Conversio and Concordia: The 'Statera prudentum'», págs. 53-64.

${ }^{56}$ Artis Cabalisticae: Hoc Est, Recondite Theologiae Et Philosophiae, Scriptorum: Tomus I. In quo Pauli Ricii Theologicos \& Philosopicos libros sunt Latini pene omnes \& Hebraei nonnulli praestantissimi Scriptores... (Basilea 1587). Hay un ejemplar en la BUBarcelona [Ref.: VD-16 P-3034]. 
De arte cabalistico de Reuchlin, el De amore de León Hebreo, la Apologia de Archangelus de Burgo Novo, el Séfer Yeșirá o Libro de la Creación, la traducción de la Porta Lucis de Chicatilla realizada por Ricius y, sobre todo, los De coelesti agricultura libri IIII del mismo Ricius, obra que, junto a la Statera prudentum, se incluyó en el Cathalogus librorum qui prohibentur de Fernando de Valdés ${ }^{57}$. La edición que Pistorius hizo de la obra de Ricius es como sigue:

Pauli Ricii doctissimi ac sapientissimi viri ex iudaica familia De coelesti agricultura libri IIII. Quibus adiunctus est in fine quarti libri Rabi Iosephi Castiliensis de Porta Lucis, Tractatus pulcherrimus ab eodem authore illustratus (ff. 5-192) :

-Liber I: In Apostolorum symbolum dialogus (ff. 5-56).

-Liber II: Quem Author in prima aeditione Sal foederis inscribi uoluit, ab ipso Authore multis in locis mutatus (ff. 57-74).

-Liber III: Statera prudentum (ff. 75-110).

-Liber IIII: Apologeticus adversus obtrectatorem Cabalae sermo (ff. 114-120).

-Porta Lucis (ff. 138-192).

-Pauli Ricii De communi ratione sacramentorum sedula lectione dignus sermo (ff. 195-198).

-De arcana Dei providentia commentariolum in Psalmum Beatus vir (ff. 199-203).

-De anima coeli compendium (ff. 204-220).

-Tractatus de sexcentis et tredecim Mosaicae legis mandatis (ff. 221-257).

-Talmudicae aeditionis farrago (ff. 258-287).

-De ter trino doctrinarum compendium (ff. 287-311).

-De investigandis statuendisque scientiarum subiectis compendium (ff. 314-323).

Bernd Roling menciona ${ }^{58}$ una obra más del converso alemán y dos traducciones:

${ }^{57}$ Cf. Cathalogus librorum qui prohibentur mandato Illustrissimi et Reverend. D.D. Ferdinandi de Valdes Hispalen(sis) Archiepiscopi, Inquisitoris Generalis Hispaniae,... (Pinciae 1559), págs. 32.

${ }^{58}$ Cf. B. Roling, Christliche Kabbalah und aristotelische Naturphilosophie im Werk des Paulus Ritius (gest. 1541) (Tübingen 2007), págs. 549-550. 
- De scientiarum subiectis (Milán 1514).

- Averrois in phisico auditu prohemium emendatum (Milán 1511).

- Averrois in duodecim Methaphisice prohemium (Milán 1511).

la primera de las cuales parece que se corresponde con la que recogemos en Gesner con el $n^{\circ}$ [13], en nuestro listado con el $n^{\circ} 6$ y en los ff. 314-323 de la edición de Pistorius de 1587; y las dos siguientes con la que en nuestro catálogo también hemos dado el $\mathrm{n}^{\circ} 6$.

Nos falta localizar, salvo error de citación, adjudicación o pérdida irremediable, la única obra del hebraísta cristiano que parece versar sobre cuestiones de retórica citada por Gesner en el $n^{\circ}$ [12], cuyo título, no obstante, presenta coincidencias léxicas con la que en nuestro catálogo ocupa el $\mathrm{n}^{\circ}$ 6: De ratione et partibus prooemii secundum rhetores /De proemio et eius partibus questio.

René Taylor descubre la presencia del De coelesti agricultura, junto a otros muchos libros de naturaleza hermética en la biblioteca oficial de Felipe II, campeón de la ortodoxia católica, como las obras de Pico, Reuchlin, Ficino, Galatino, Dee, Beroaldo, Pomponazzi, Tritemio, Cardano, lo que le lleva a concluir ${ }^{59}$ que este hecho «da ciertamente un mentís a la tan repetida afirmación de que, gracias a la vigilancia del Santo Oficio, España se libró por lo general de la superstición, la magia y otras tendencias poco ortodoxas en aquella época».

En España, el eco de las obras de Ricius también lo hallamos, como adelantamos en la introducción del presente trabajo, en Gómez Miedes, quien cita en sus Comentarii de sale la obra titulada Sal foederis. El catálogo ofrecido por Gesner en su Bibliotheca Uniuersalis (cf. supra apud Gesnerum opus $n^{o}$ [3]) no deja lugar a dudas: se trata de la Philosophica, Prophetica et Talmudistica disputatio. Una ojeada a la portada de la edición de 1514, localizada en la BN de Francia, nos muestra una especie de emblema encima del título de la obra que representa a un erizo con una orla encima en la que puede leerse la leyenda sAL FEDERIS (sic) (Figura 1) ¿Utiliza Gómez Miedes esta denominación de la obra, «inofensiva» para un cristiano frente al más comprometido de Philosophica, Prophetica et Talmudistica disputatio..., como un caso de «enmascaramiento de la cábala en España»?

Recordemos de nuevo que, aunque los Opera omnia de Ricius estuvieron prohibidos en España en 1583, es decir, cuatro años después de la mención por parte de Miedes del Sal foederis del hebraísta cristiano, desde el año 1551 aparecen prohibidos títulos de sus obras en los catálogos del siglo XVI, y en 1556 el De

${ }^{59} C f$. R. TAYlor, «Los Libros Herméticos de Juan de Herrera y Felipe II», en R. TAYLOR, Arquitectura y Magia. Consideraciones sobre la Idea de El Escorial (Madrid 1995), págs. 137-141. 


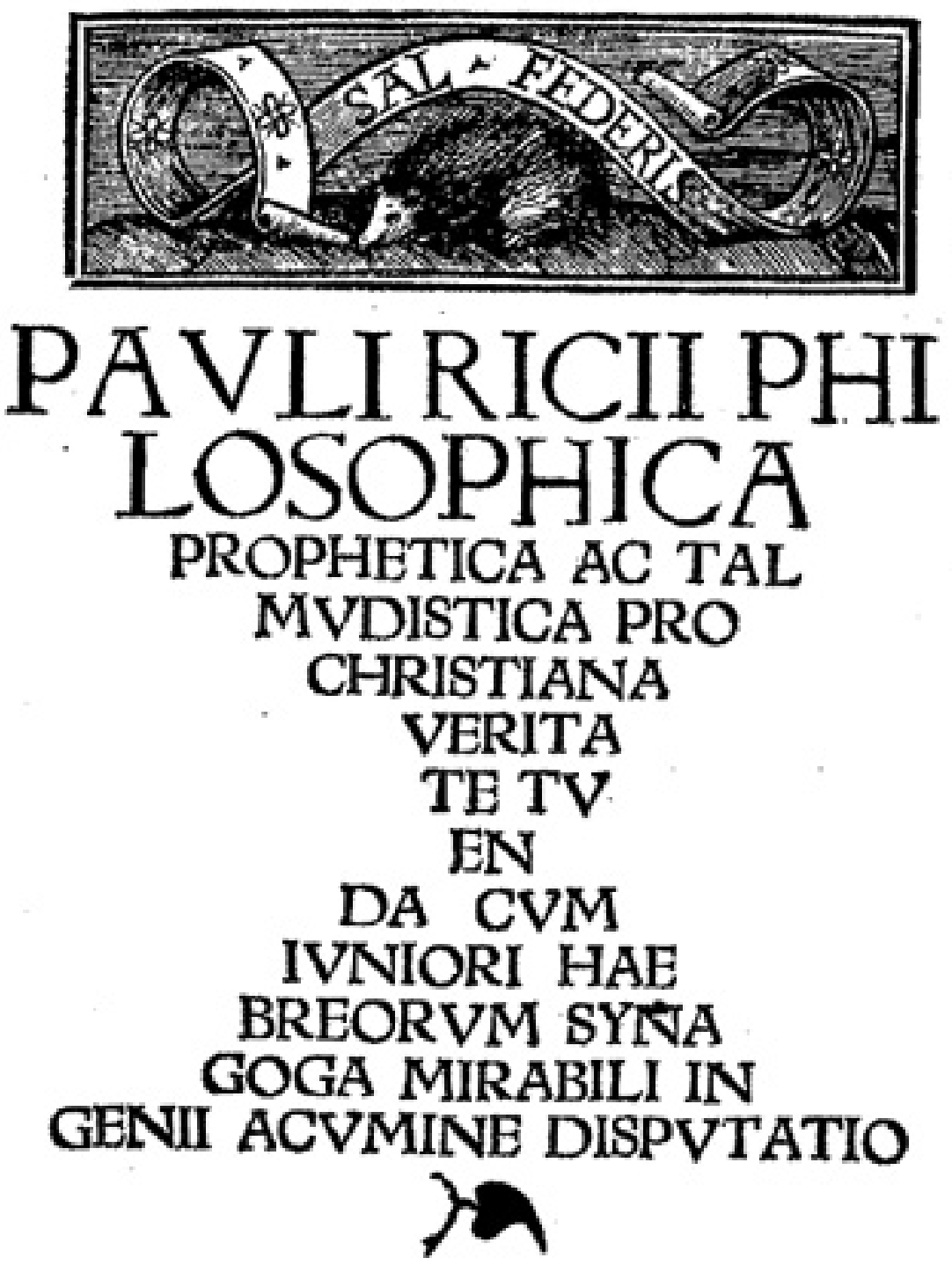

Fig. 1. Philosophica, prophetica ac talmudistica, pro christiana veritate tuenda cum iuniori Haebreorum synagoga mirabili ingenii acumine disputatio, Augusta Vindelicorum 1514 (ALO: Universitätsbibliothek Innsbruck, sign. UBI-HB-S 221.159/Adl.1). 
coelesti agricultura ${ }^{60}$, que engloba, como hemos visto, las principales obras del hebraísta cristiano, entre las cuales, la mencionada por Gómez Miedes en sus Commentarii de sale de 1579. Las obras de Ricius que aparecen en los catálogos de libros prohibidos en el siglo XVI son ${ }^{61}$ :

Opera omnia: Roma 1559 y 1564, 817 (VIII, 640). España 1583, 1415 (VI, 501).

De coelesti agricultura : Portugal 1551; España 1559, 354 (V, 424-425).

De communi sacramentorum ratione : Roma 1557, 817 (VIII, 640-641).

Statera prudentum : Portugal 1551, 420; 1561, 1116 (IV, 326-327, 418). España 1551, 51; 1559, 391 (V, 243, 437) ; 1583, 1577 (VI, 538-539). Roma 1557, 00139, 817 (VIII, 240-241, 640-641); 1596, 1046 (IX, 717-718).

Tractatus in Symbolum Apostolorum : Roma 1557, 817 (VIII, 640).

Que Sal Foederis es el título que engloba la obra cabalística de Ricius se explica en el exordio ${ }^{62}$ :

Summa autem huius indaginis intentio est sacram Christi religionem a iudaeorum calumniis (superno cooperante spiritu) protegere eandemque cabalistico intellectu comprobare. Non ueluti omnimode noua construendo, sed quaedam iam constructa, insipida tamen, sal ipsum (ut Leuitico tertio) apponendo, sapida reddere nitar, unde et Sal foederis praesens nostrum opus appellari libuit. Quattuor igitur tractatibus potissimum haec praefata intentio consumitur. Primus causam iudaeorum perfidiae ostendit. Secundus quod, admissis Mosaicae obseruantiae fundamentis, uerus Christicola salutem assequitur. Tertius quod nemo nisi per Christi fidem fieri potest beatus. Quartus quaedam Cabalistarum recondita aperiet fundamenta, quibus Catholicae fidei ueritas planius altiusue elucescat.

\footnotetext{
${ }^{60}$ Cf. supra nota 57.

${ }^{61}$ Cf. J. Martínez de Bujanda (dir.), Thesaurus de la littérature interdite au XVI ${ }^{e}$ siècle: auteurs, ouvrages, éditions avec addenda et corrigenda (Genève 1996), pág. 340

${ }^{62}$ Cf. Pauli Ricii Philosophica, prophetica ac talmudistica, pro christiana veritate tuenda..., 1514, f. [8v]. Trad.: 'El objetivo primordial de este ensayo es proteger la sagrada religión cristiana contra las calumnias de los judíos (con la ayuda del espíritu celestial) y confirmarla mediante la inteligencia de la cábala. Y como no hay que fundar de ninguna manera una religión nueva, sino que al estar ya en cierto sentido fundada, debido, sin embargo, a su insipidez, he de esforzarme en dotarla de sabor sirviéndole esa sal (que se lee en Levítico 3), es por ello por lo que me pareció bien llamar a la presente obra La sal de la alianza. Así pues, este empeño descrito se consume sobre todo en cuatro tratados. El primero muestra la causa de la perfidia de los judíos. El segundo explica que, si se admiten los fundamentos del respeto a las leyes mosaicas, se asegura la verdadera salvación del cristiano. El tercero, que no hay nadie que pueda ser bienaventurado salvo a través de la fe de Cristo. El cuarto mostrará los fundamentos ciertamente recónditos de los cabalistas, con los que la verdad de la fe católica brillará con mayor evidencia y claridad'.
} 
Ricius estructura el Sal foederis en cuatro partes, la última de las cuales «abre» los recondita Cabalistarum fundamenta, es decir, lo que circuló de forma independiente en forma de libellus con el título de In cabalam Isagoge. El Israelita precisa lo que él entiende por «cábala» al principio de su tratado ${ }^{63}$ :

Cabala ea facultas dicitur quae diuinorum humanorumque noticiam per Mose legem allegorico sensu insinuat, quam quia non calamo, sed auditu, non argumentandi tramite, sed fide aperire licuerit, cabalam, quod receptionem sonat, uocari libuit.

François Secret constató ya hace algunos años ${ }^{64}$ ciertas divergencias entre el texto de la In cabalistarum seu allegorizantium eruditionum Isagoge de 1515 y el de 1541, que formaba el libro II del De coelesti agricultura, reproducido años después, en 1587, por Pistorius.

Ricius no sólo modifica el número de theoremata (50 en lugar de 66), sino también los acompaña de apéndices tan interesantes que el célebre jesuita Athanasius Kircher los utilizó en su largo estudio consagrado a la kabbala en su Oedipus Aegyptiacus (Roma 1635, t. II, pp. 209-360), en especial el theorema L y último de la Isagoge de 1541, pero sin citar ni una sola vez a Paulus Ricius ${ }^{65}$.

En el mencionado estudio, Secret escribe que la primera edición del tratado realizada en Pavía, en 1510, aparece precedida de un prefacio «signée par un confrère de l'auteur du Libellus de literas sanctus et de la Scechina, Joannes Benedictus Moncetus, Heremitarum frater» ${ }^{66}$. Hemos consultado en $A L O$ (Austrian Literature Online) ${ }^{67}$ la edición de 1510, que aparece precedida de un epigrama del médico Georgius Pharelius, una epístola de Ricius al moderator Insubris Regii Senatus Iafredus Carolus, y una praefatio del autor (no he halla-

${ }^{63}$ Cf. Pauli Ricii In cabalistarum seu allegorizantium eruditionem isagoge [In colof.: Augustae impressum. Anno MDXV], f. 5r. Trad.: 'Se llama cábala a la facultad que sugiere alegóricamente la noción de lo divino y lo humano a través de la Ley de Moisés, y dado que no fue permitido revelarla con la pluma, sino oralmente, y no con la senda de la argumentación, sino con la fe, pareció bien llamarla cábala, que significa recepción'.

${ }^{64} C f$. F. SeCRET, «Notes sur Paulus Ricius et la kabbale chrétienne en Italia», Rinascimento 11 (1960), págs. 169-192; SECRET, La kabbala cristiana, págs. 107-120.

${ }^{65}$ Otros trabajos de Secret donde aparece citado Ricius son: La Kabbale. De arte cabali tica; F. SECRet, Postel revisité. Nouvelles recherches sur Guillaume Postel et son milieu (Paris 1998). Este erudito lo hace hermano de Augustinus Ricius, autor del De Motu octauae sphaerae, opus matematica atque philosophia plenum (Lutetiae 1521) y protagonista de una de las obras de Ricius, añadiendo datos nuevos indispensables para adentrarse en el estudio filológico de la obra del converso alemán, aunque con algunas inexactitudes bibliográficas.

${ }^{66} C f$. SeCRet, «Notes sur Paulus Ricius», pág. 169.

${ }^{67} \mathrm{http} / / /$ www.literature.at/webinterface/library/ALO-BOOK_V01?objid=13462. 
do la praefatio del mencionado Joannes Benedictus Moncetus). Dicha edición (Figura 2) está estructurada como sigue:

\section{Iposuli ifraelite in cabaliftar rum:feu allegozizan tium eruditionent 3ragoge. I. \\ CEum paiulegio pcefio a franco Rege cbziftianifimo.}

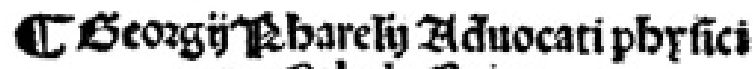 De Eabala Epig.}

Dibe pererrato Sacraria grçca recondant

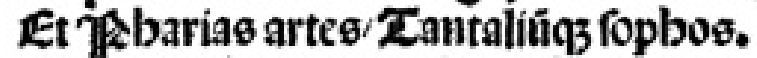
Zrrbanum Toulus ç̧leftis Cabala mifti Zappcrit in Illsofem:cui ocus auctoz adeft. Dic naturę ozdo:\{uperum penetralia fulgent: Phobilioza deo oogmata:quis oocuit.

Fig. 2. In cabalistarum seu allegorizantium eruditionem sagoge, Papiae, per Magistrum Jacob Burgofrancho 1510 (ALO: Universitätsbibliothek Innsbruck, sign. UBI-HB-S 155.F.32/Adl).

Pauli israelite in cabalista /rum: seu allegorizan / tium eruditionem / Isagoge [In colof.: Papie impresse per magistr. Jacob Burgofrancho. Anno domini 1510. die 10 octobris]

- Georgii Pharelii Aduocati physici de Cabala epig(ramma) [In Port.] .....f. [1r] 
- Aequissimo Insubris Regii senatus et sui, et litterariae militie moderatori Iafredo Carolo Paulus Ricius Israelita suppliciter se commendat ........ f. $2 \mathrm{r}-2 \mathrm{v}$

- In Cabalam Isagogae PRAEFATIO .....................................................................f. $3 \mathrm{r}$

- IN CABALAM YSAGOGE ............................................................................f. 4r-f. 26v

- Praeuiae oratiunculae (66) .............................................................ff. 4r- $7 \mathrm{r}$

- Conclusiones ...........................................................................ff. $7 \mathrm{v}-25 \mathrm{r}$

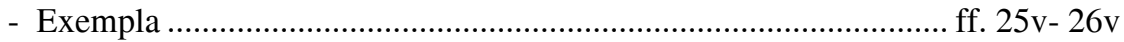

\section{CONCLUSIÓN}

Queda, en definitiva, una ingente y compleja tarea de estudio, edición crítica y traducción de la obra de uno de los principales difusores europeos del movimiento cabalístico cristiano en el siglo XVI, fundamentalmente de tres obras cuya influencia parece que fue mayor, al menos en Europa y, particularmente, en España, es decir, la Isagoge in Cabalam, el Sal foederis y la traducción latina del Sefer Ša 'aré Orá de R. Yosef b. Abraham Chicatilla, la Porta Lucis.

Sirva, pues, el presente estudio para abrir de alguna manera una puerta en nuestro país a la investigación de la obra de Paulus Ricius ${ }^{68}$, cuyo fin último sea poder evidenciar de forma fehaciente el grado de influencia de los cabalistas y hebraístas cristianos europeos en nuestros místicos y humanistas con pruebas textuales y filológicas ${ }^{69}$.

Recibido: $13 / 11 / 2008$

Aceptado: 02/09/2009 (versión final)

${ }^{68}$ Además de la presencia y posible influencia de Ricius en las Paradoxae Quaestiones de Pedro Ciruelo y en los Commentarii de sale de Gómez Miedes, Kottman liga a fray Luis con el converso y cabalista cristiano Paulus Ricius, aunque, según García de la Concha, el místico español no necesitaba «el estímulo de la privilegiada valoración de la Cábala para prestar atención al Cantar de los Cantares», cf. K. Kottman, Law and Apocalipse: The Moral Thought of Luis de León (The Hague 1972); V. GARCía DE LA CONCHA, Al aire de su vuelo. Estudios sobre Santa Teresa, fray Luis de León, san Juan de la Cruz y Calderón de la Barca (Barcelona 2004), págs. 201-202.

${ }^{69}$ El presente trabajo está incluido en el Proyecto de Investigación FFI2009-10133 de la DGICYT y en el Proyecto de Excelencia PAI05-HUM-00860 de la Junta de Andalucía. Agradezco, por otra parte, a la Dra. Dña. Violeta Pérez Custodio su atenta lectura de nuestro original. 